\title{
CRESCIMENTO ECONÔMICO REGIONAL NO BRASIL: A EDUCAÇÃO COMO FATOR DE CONVERGÊNCIA - 1970/1996
}

\author{
José Raimundo Vergolino ${ }^{1}$ \\ Antônio Pessoa Nunes Neto ${ }^{2}$ \\ Marcelo Andrade Bezerra Barros ${ }^{3}$
}

\section{INTRODUÇÃ̃o}

O processo de desenvolvimento econômico de uma economia pode ser caracterizado pelo crescimento da renda associado a uma melhor qualidade de vida de sua população. Dada a relevância do tema, esse assunto tem recebido uma crescente atenção por parte dos economistas que procuram determinar as variáveis condicionantes desse processo. Nesse contexto, o debate acerca da existência ou não de convergência da renda entre países e regiões vem contribuindo para uma melhor compreensão de uma importante face do processo de desenvolvimento econômico: questão espacial.

O objetivo principal deste trabalho é verificar a existência de um processo de convergência das rendas per capita nas regiões brasileiras no período de 1970 a 1996, a partir de uma perspectiva espacial pouco estudada em trabalhos do gênero, qual seja as microrregiões homogêneas. Ademais, procurar-se-á investigar a importância dos investimentos em capital humano nesse processo. Nesse contexto, o presente estudo tenciona responder às

1 Ph.D. em Economia e professor do Departamento de Economia - UFPE. quantum@hotlink.com.br

2 Bacharel em Economia pela UFPE e consultor de empresa. antpess@excite.com

3 Mestre em Economia/PIMES, p rofessor da Faculdade Boa Viagem e consultor de empresa - Planisa. planisa@elogica.com.br 
seguintes indagações: Existe um processo de convergência microrregional nas regiões brasileiras? Em caso afirmativo, qual a velocidade pela qual este se processou? Quais os fatores associados a cada região que contribuíram para este resultado?

Afim de responder a essas importantes questões, o presente trabalho está estruturado da seguinte forma: a primeira seção apresenta as bases teóricas do modelo de análise, a segunda seção se ocupa com uma breve resenha sobre alguns outros estudos que abordaram crescimento e convergência regional; a base de dados será objeto de discussão da terceira seção; a quarta seção apresenta uma breve caracterização das regiões; na quinta seção são arrolados os principais resultados do estudo, seguido das conclusões constantes na sexta seção.

\section{BASES TEÓRICAS DO MODELO DE ANÁLISE}

O modelo desenvolvido por Robert Solow (1956) constitui o ponto de partida para entender o processo de crescimento econômico de uma economia na perspectiva de longo prazo. Os economistas regionais embasados no paradigma neoclássico procuraram estilizar o modelo de Solow para o contexto regional. Uma importante contribuição foi dada por Smith (1975), que propôs um modelo no qual a relação capital/trabalho de uma economia é relacionada ao aumento das taxas de crescimento do trabalho e do capital. No modelo proposto, assume-se que o produto numa dada região é dado por uma função de produção agregada do tipo Cobb-Douglas com dois fatores: capital (K) e trabalho (L).

$$
\mathrm{Y}=\mathrm{K}^{\alpha} \mathrm{L}^{(1-\alpha)} \quad \text { onde } 0<\alpha<1
$$

A hipótese subjacente é que ambos os fatores são totalmente empregados e o preço do produto é constante. Os fatores de produção serão remunerados pelos seus respectivos produtos marginais. Assume-se que os mercados de bens e fatores são competitivos. O estoque de Trabalho é fornecido pela seguinte expressão:

$$
\mathrm{L}=\mathrm{L}^{\rho \mathrm{t}}
$$

Onde: Lé a oferta de trabalho existente e $\rho$ t é o nível de progresso técnico. Substituindo (2) em (1), encontraremos: 


$$
y=Y / L=K^{\alpha} L^{-\alpha} e^{\rho t(1-\alpha)}
$$

Fazendo a derivada do logaritmo natural de (3), obtém-se uma expressão em termos de taxas de crescimento da renda per capita:

$$
y=\alpha K^{*}-\alpha L^{*}+(1-\alpha) \rho
$$

A equação (4) nos fornece que a taxa de crescimento do produto per capita depende da taxa de crescimento do trabalho e capital. A próxima etapa é explicar as variáveis que influenciam as taxas de crescimento do capital $\left(\mathrm{K}^{*}\right)$ e do trabalho $\left(\mathrm{L}^{*}\right)$.

No modelo ora proposto, cada região é vista como uma economia aberta, em que existe uma relação capital-trabalho única para cada região, de tal sorte que não existem incentivos para realocar recursos dentro de uma mesma região. Esse fato induz os fatores de produção a fluírem de uma região para outra, objetivando a busca de maiores rendimentos. Ao se introduzir o investimento, temos que levar em conta a variável poupança, que é definida como uma fração positiva do produto, e a "la Solow", tem-se:

$$
\mathrm{S}=\mathrm{sY} \text { onde } 0<\mathrm{s}<1
$$

Os indivíduos que detêm poupança decidirão se as mesmas serão canalizadas para investimentos locais ou transferidas para outras regiões por meio da comparação entre o custo de oportunidade do capital a nível nacional - taxa interna média de retorno do país ( $r n$ ) e a taxa média de retorno de dentro de uma região (r). K indica o estoque de capital regional. Assim, podese definir o movimento líquido de capital (MLK) como:

$$
\operatorname{MLK}=\mathrm{v}\left(\mathrm{r}-\mathrm{r}_{\mathrm{n}}\right) \mathrm{K} \text { onde } \mathrm{v}>0
$$

Pode-se concluir que as oportunidades de investimento serão maiores na região onde o nível absoluto de capital (K) é maior, dado o diferencial de retorno. O próximo passo é definir o nível de investimento líquido regional (KL). Este será definido como a soma da poupança da região, mais o investimento líquido de capital inter-regional, menos a depreciação do capital:

$$
\mathrm{KL}=\mathrm{S}+\mathrm{MLK}-\mathrm{qK}
$$

onde: S é a poupança regional; MLK é o movimento líquido de capital e (q) é a taxa de depreciação do capital na região. Considerando o produto marginal 
do capital igual a Y/K e substituindo as equações (5) e (6) em (7) e fazendo as transformações necessárias, iremos ter a taxa de crescimento do capital:

$$
\mathrm{K}^{*}=[(\mathrm{s}+\mathrm{v} \alpha) \mathrm{Y} / \mathrm{K}]-[(\mathrm{v} \alpha \cdot \mathrm{Ya} / \mathrm{Ka})+\mathrm{q}]
$$

Logo pode-se dizer que o crescimento líquido do estoque de capital está relacionado positivamente com o produto por unidade de capital, pois $\mathrm{s}$, v e $\alpha$ são positivos.

A próxima etapa está em definir os determinantes do fator trabalho. As modificações na força de trabalho são provocadas pelo crescimento natural da população e pela migração líquida. Considera-se a taxa de crescimento natural da população (DP) e a taxa exógena de participação da força de trabalho no total da população da região $(\mathrm{L} / \mathrm{P})$ constantes e iguais em todas as regiões. (DM) é a taxa de crescimento da migração líquida. Dessa forma, a variação na força de trabalho será dada por:

$$
\mathrm{DL}=(\mathrm{L} / \mathrm{P}) \cdot(\mathrm{DP}+\mathrm{DM})
$$

A taxa de crescimento da força de trabalho será dada pela divisão da expressão (9) por L:

$$
\mathrm{DL} / \mathrm{L}=\mathrm{L}^{*}=\mathrm{DP} / \mathrm{P}+\mathrm{DM} / \mathrm{P}
$$

A expressão (9) se reduz a:

$$
L^{*}=M^{*}+n
$$

onde $\mathrm{M}^{*}$ é a taxa de crescimento da migração líquida e n é a taxa de crescimento da população. Uma hipótese fundamental do modelo é que o principal motivo para migrar está associado ao diferencial entre o salário regional e o salário médio nacional. Assim sendo, podemos colocar a função de migração líquida como:

$$
\mathrm{DM} / \mathrm{P}=\mathrm{M}^{*}=\mathrm{d}\left(\mathrm{W}-\mathrm{W}_{\mathrm{n}}\right)+\mathrm{n} \quad \mathrm{d}>0
$$

Assim $\mathrm{M}^{*}$ estará positivamente relacionado com a diferença entre o salário regional (W) e o salário a nível nacional (Wn). Isso ocorre porque considerar-se-á a taxa de crescimento da população ( $\mathrm{n}$ ) constante e a mesma em todas as regiões. Combinando-se as equações (4), (8), (11) e (12), chega-se à expressão geral do modelo, que indica a trajetória de crescimento da renda.

$$
y^{*}=(1-\alpha) \rho-\alpha n-\alpha M^{*}+\alpha K^{*}
$$


Nesse modelo, a região com baixo nível de produto por trabalhador terá uma maior expansão da taxa de crescimento do que a região rica e, no longo prazo, todas as regiões tenderiam a convergir para um nível comum da renda per capita. No modelo acima, a produtividade marginal do capital é função inversa da razão capital/trabalho, de tal sorte que o capital irá fluir para as regiões onde esta razão é baixa, em busca de melhores taxas de retorno. Os salários são uma função direta da relação capital/trabalho e, dessa forma, o trabalho sairá da região que apresente baixo produto por trabalhador para uma região com produtividade mais elevada em busca de melhores remunerações. Esse fluxo dos fatores na direção contrária à sua abundância relativa fará com que haja uma equalização de suas respectivas remunerações, levando, assim, a convergência das rendas per capita regionais.

\subsection{Os tipos de convergência}

Afirma-se que um grupo de regiões estará convergindo para uma média global se as dispersões da renda per capita tenderem a decrescer ao longo do tempo. A idéia subjacente a este conceito é que a variância da renda per capita das diversas regiões estaria declinando e convergindo para um valor comum. Se representarmos $t$ como o desvio-padrão no tempo t e $t+T$ como o desvio-padrão no tempo $\mathrm{t}+\mathrm{T}$, podemos representar o conceito exposto da seguinte forma: $\mathrm{t}+\mathrm{T}<\mathrm{T}$. Trata-se da convergência.

A interpretação da convergência (leva em consideração a associação entre o nível de renda per capita inicial na região e o crescimento da mesma ao longo do tempo. A convergência (pode ser examinada sob duas óticas: convergência absoluta e convergência condicional.

No modelo de crescimento neoclássico, a hipótese de retornos decrescentes do capital implícito na função de produção faz com que o capital mova-se para regiões que apresentam baixa relação capital/trabalho, em que a taxa de retorno é superior. Se a única diferença entre dois países (ou região) for o estoque inicial de capital, o paradigma neoclássico prediz que as economias pobres irão crescer mais rápido do que as ricas (SALA-I-MARTIN, 1996).

O significado desse conceito é mais profundo do que parece a princípio. O processo de convergência absoluta requer que as economias apresentem todas suas características estruturais de forma semelhante, sendo a única diferença existente o nível inicial de capital. Em outras palavras, é necessário um steady state igual (GALOR, 1996).

A hipótese da convergência absoluta é muito forte quando observase o atual estágio das economias mundiais. A heterogeneidade nas estruturas 
econômicas, sociais e políticas entre os países tende a gerar posições de equilíbrio (steady state) diferentes. Diante do contexto acima, a veracidade da hipótese da convergência absoluta torna-se de difícil comprovação. Entretanto, em países com características similares (como os da OECD) e regiões dentro de um determinado país, onde as similitudes estruturais são bastante grandes, permitindo a suposição de um steady state comum, será possível encontrar o fenômeno da convergência absoluta (SALA-I-MARTIN, 1996).

No conceito anterior foi dito que um processo de convergência absoluto acontece quando países (ou regiões) tendem a crescer a taxas mais elevadas do que os países ricos. A condição assumida é que o estado de equilíbrio (steady state) seja igual para todos. Entretanto, o que se observa na realidade são economias com diferentes estruturas (tecnologia, taxa de poupança, taxa de crescimento populacional etc). Se as economias apresentam diferentes steady state não podemos falar em convergência absoluta e sim em condicional. A taxa de crescimento de uma economia será positivamente relacionada com a distância que separa a situação inicial do ponto de equilíbrio (steady state). Essa situação é denominada convergência condicional (SALA-IMARTIN, 1996).

\section{UMA BREVE RESENHA DA LITERATURA}

Uma significativa literatura tem sido escrita com o objetivo de testar a hipótese da convergência das rendas per capita, por meio de séries estatísticas de diversos países e regiões do mundo. Esses estudos enveredam em busca da constatação empírica relativa às conclusões teóricas, referentes à questão, utilizando dois focos de análise: a dispersão cross-sectional (a e b convergência) e os estudos de séries temporais. Em termos espaciais, os trabalhos sobre convergência da renda per capita podem ser divididos em dois grupos: as comparações entre países (cross-country) e as comparações entre regiões ou Estados de um determinado país (cross-regional).

O desenvolvimento de uma base de informações mais sofisticada e mais ampla, juntamente com a incorporação de novas concepções, na teoria de crescimento, permitiram a investigação do fenômeno da convergência em diversos países (cross-country). Nessa linha de raciocínio, pode-se citar o clássico estudo realizado por Baumol (1986), que encontrou forte evidência em favor de um processo de convergência, principalmente para os países mais industrializados. As conclusões do autor apontam para a existência de "clubes de convergência" compostos de países com características homogêneas. A 
refutação do estudo de Baumol foi feito por De Long (1988), o qual argumentou que, ao ampliar a amostra utilizada, esta passou a indicar uma não convergência das rendas per capita.

A importância dos investimentos em capital humano para o crescimento econômico sob a óptica da convergência foi objeto de análise nos estudos de Barro (1991) e Cho (1994). As conclusões desses autores indicam que os países que mais investem em capital humano são os que mais crescem, haja vista uma maior absorção de novas idéias e tecnologia por parte da população, resultando numa expansão da produtividade. Cho sugere que o aumento da produtividade está associado aos investimentos em capital humano. Estes são responsáveis, em grande parte, pelo sucesso das economias denominadas "Tigres Asiáticos".

A segunda perspectiva espacial utilizada nos estudos sobre convergência da renda per capita reporta-se à análise de regiões ou Estados dentro de um determinado país. Nesse contexto, as similitudes entre essas regiões provenientes de um sistema político, social e econômico comum proporcionam uma investigação mais realista acerca da hipótese contida na teoria neoclássica.

Barro e Sala-I-Martin (1995) examinaram a questão regional de longo prazo nos estados americanos, utilizando dados que abarcam o período de 1880 e 1990. A incorporação de novos elementos ao modelo de crescimento neoclássico permitiu que os autores desenvolvessem uma metodologia mais refinada para estudar a questão. Nesse contexto, os resultados evidenciados pelos autores indicam um nítido processo de convergência da renda per capita inter-regional nos EUA com uma taxa de cerca de $2 \%$ ao ano. Conclusões semelhantes foram encontradas para as prefeituras japonesas e para alguns países europeus. Os autores alertam que o fenômeno da convergência apresenta um caráter condicional a certos fatores, como a taxa de fertilidade, o nível de capital humano e as políticas governamentais. Economias com tais características semelhantes tendem a um processo de convergência absoluta.

A partir da metodologia proposta por Barro e Sala-I-Martin (1995), diversos estudos foram elaborados, em vários países, a fim de avaliar a existência do fenômeno da convergência. Cardenas e Pontón (1995) examinaram a questão na Colômbia e concluíram, por um processo de convergência da renda per capita entre os estados colombianos, que se processa a uma taxa de $4 \%$ ao ano. Os investimentos em educação no processo de crescimento também foram alvo de investigação pelos autores. A esse respeito, eles revelam que as regiões que mais investem no setor educacional são aquelas que mais cresceram no período analisado. 
Um outro estudo que examina a questão do crescimento econômico regional em um país subdesenvolvido foi o realizado por Ramon e Batiz (1996). Os autores identificaram a ocorrência de convergência entre os estados mexicanos no período de elevada expansão do PIB nacional, ocorrido entre 1970 e 1985. Nesse intervalo de tempo, a velocidade de convergência estimada foi de $2,4 \%$ ao ano.

No caso do Brasil, a problemática do crescimento econômico desigual entre as regiões tem sido alvo de diversos ensaios acadêmicos, que investigam o padrão comportamental do desenvolvimento regional, a fim de mapear alternativas que possam ser utilizadas para reverter a assimetria espacial daquele processo. À luz dessa preocupação, a análise da convergência entre as rendas per capita das diversas regiões brasileiras tornou-se um dos assuntos, dentro da economia regional, que mais tem sido objeto de discussão.

Uma importante contribuição ao estudo do tema foi dada por Azzoni (1996), que analisou o assunto em termos do país como um todo e entre as regiões brasileiras. A análise realizada aponta para a redução das desigualdades regionais ao longo do tempo. Na perspectiva inter-regional, os resultados apontaram um quadro adverso: o Sul e o Sudeste brasileiro apresentam um processo de convergência das rendas per capita de seus Estados, enquanto que nas Regiões Norte e Nordeste a tendência é divergente

Nesse contexto, as conclusões não corroboram a hipótese da convergência absoluta da renda regional brasileira. Por outro lado, quando as diferenças entre as regiões são explicitadas por meio de variáveis dummies, a hipótese é aceita. A velocidade de convergência, nesse caso, está situada num intervalo de $1,37 \%$ a $2,27 \%$ ao ano.

\section{A BASE DE DADOS: OS PIB'S DAS MICRORREGIÕES}

As estimativas de PIB mais utilizadas no Brasil, dentre elas a do $\mathrm{IBGE}^{4}$, têm como fator limitante de análise a não-reprodução dos mesmos a nível das microrregiões ou municípios, contemplando apenas os Estados da Federação. Com vistas a preencher essa lacuna nas informações que utilizam um maior grau de desagregação, foi elaborada uma metodologia auxiliar para

4 Instituto Brasileiro de Geografia e Estatística. O IBGE tem se notabilizado, ao longo dos anos, pela produção dos indicadores de PIB mais largamente utilizados no Brasil. 
o cálculo das mesmas. Em adição, a inexistência de informações censitárias cobrindo todo o período estudado levou à adoção de procedimentos metodológicos distintos para diferentes períodos.

A elaboração de censos econômicos, contemplando 1970, ano-base deste trabalho, propiciou a coleta de informações quanto à participação relativa de cada município no valor adicionado de cada setor econômico - indústria, comércio, serviços e agropecuária - calculando-se a partir daí sua participação relativa dentro de cada Estado respectivo. No que diz respeito ao ano de 1996, foram utilizados dados de produção, tais como consumo de energia elétrica e produção agropecuária, abarcando respectivamente os setores industrial e agropecuário. Para os setores de comércio e de serviço, utilizou-se dados de emprego, disponíveis segundo publicação do Ministério do Trabalho. Tal como no período anterior, os dados para 1996 foram obtidos para as municipalidades, calculando-se, então, sua participação dentro do Estado e multiplicando-se, em seguida, pelo PIB respectivo.

A mensuração do PIB microrregional foi realizada mediante o somatório dos dados setoriais municipais, já normalizados pelo PIB estadual fornecido pelo IBGE. Para a estimação do PIB per capita das micros, adotou-se procedimento análogo, primeiramente por meio do levantamento dos dados populacionais municipais e posterior agregação para micros. Em seguida, calculou-se a razão PIB/ População, chegando-se aos valores per capita.

\subsection{As variáveis educacionais}

As estatísticas de educação utilizadas neste trabalho reportam àquelas publicadas pelos censos demográficos de 1970 e de 1991. Por seu turno, elas contabilizam o estoque de pessoas com os níveis elementar, de $1 .^{\circ}$ e de $2 .^{\circ}$ graus, e não apenas o número de matriculados. De forma análoga ao PIB, as informações primárias das variáveis educacionais estão numa óptica municipal, sendo posteriormente agregadas para o contorno das microrregiões.

Graças à uniformidade metodológica entre as publicações mais antigas e as mais recentes, pôde-se também estabelecer uma comparação da evolução do quadro educacional do país - e também das regiões - ao longo do período estudado, contribuindo para o enriquecimento da análise ao mostrar mais claramente a expansão ocorrida no setor educacional brasileiro. 


\section{BREVE CARACTERIZAÇÃO DAS REGIÕES}

$\mathrm{O}$ intenso processo de desenvolvimento experimentado pela economia brasileira a partir da década de 70 constitui-se num bom ponto de partida para o entendimento das implicações regionais de algumas variáveischave de tal processo - destacando-se o PIB per capita, a população e o nível educacional.

Com um PIB per capita de US\$ 4.945 em 1996 contra apenas US\$ 2.639 em 1970, o Brasil passou a integrar o grupo dos países de renda média alta, segundo classificação adotada pelo Banco Mundial ${ }^{5}$. Houve nesse período uma tendência de convergência nas rendas regionais, indicando redução no quadro geral de disparidades. Entretanto, mesmo que os efeitos dessa transformação se tenham feito sentir em todo o território, ainda reside nesse quesito um grande gap inter-regional, uma vez que algumas regiões vêm conseguindo colher resultados mais consistentes, mediante uma melhora mais acentuada ocorrida ao nível intra-regional.

A Tabela 1 apresenta informações relativas ao PIB per capita para as regiões brasileiras e também para o Brasil, bem como as taxas médias de crescimento para os períodos selecionados. Uma boa notícia é que regiões inicialmente mais pobres vêm crescendo a taxas mais elevadas, ajudando na redução do quadro geral de disparidades. Entretanto, é visível a distância existente entre as regiões. Ainda que o PIB per capita da região mais rica fosse 3,21 vezes maior que a região mais pobre em 1996, contra 3,93 vezes em 1970, isso torna possível a existência de pelo menos duas faixas bastante distintas de riqueza. Tal como é o objetivo deste trabalho, procurar-se-á verificar mais adiante se a estrutura microrregional pertinente a cada uma dessas regiões, condicionada a variáveis especialmente escolhidas, é capaz de acelerar esse processo de convergência.

No tocante à população, um dos fenômenos mais importantes ocorridos no período em estudo foi o da migração campo-cidade. Com efeito, cerca de $44 \%$ da população brasileira era de origem rural em 1970, ao passo que em 1996 esse percentual reduziu-se substancialmente para 21\%. Outro ponto digno de nota é a perda relativa de população de algumas regiões, dentre elas o Nordeste e o Sul, entre 1970 e 1996, concomitantemente ao aparecimento de novas regiões de colonização no Centro-Oeste, além da intensificação do povoamento no Norte. Os percentuais relativos da população total concernentes

$5 \quad$ World Development Report, 1996. 
Tabela 1 - REGIÕES DO BRASIL - PRODUTO INTERNO BRUTO PER CAPITA (US\$) E TAXAS DE CRESCIMENTO (\%) - 1970 - 1996

\begin{tabular}{lcccccccc}
\hline \hline \multicolumn{1}{c}{ Regiões } & \multicolumn{3}{c}{ PIB per capita - US\$ 1,00 de 1998 } & \multicolumn{5}{c}{ Taxas de Cresc. - em \% } \\
& 1970 & 1980 & 1990 & 1996 & $70 / 80$ & $80 / 90$ & $90 / 96$ & $70 / 96$ \\
\hline \hline Norte & 1.382 & 2.849 & 3.211 & 3.315 & 7,50 & 1,20 & 0,53 & 3,42 \\
Nordeste & 1.033 & 1.945 & 2.047 & 2.189 & 6,53 & 0,51 & 1,12 & 2,93 \\
Sudeste & 4.059 & 6.794 & 6.194 & 7.044 & 5,29 & $-0,92$ & 2,17 & 2,14 \\
Sul & 2.527 & 5.040 & 5.016 & 5.320 & 7,15 & $-0,05$ & 0,99 & 2,90 \\
Centro-Oeste & 1.470 & 3.419 & 3.508 & 4.066 & 8,81 & 0,26 & 2,50 & 3,99 \\
\hline \hline Brasil & 2.639 & 4.696 & 4.445 & 4.945 & 5,93 & $-0,55$ & 1,79 & 2,45 \\
\hline \hline
\end{tabular}

FONTE: IBGE. Censos Econômicos e Demográficos, diversos anos.

a cada uma das grandes regiões brasileiras encontravam-se dispostos em 1996 tal como segue: Sudeste $(43,16 \%)$; Nordeste $(28,83 \%)$; Sul $(15,16 \%)$; Norte (7,29\%); Centro-Oeste $(5,58 \%)$.

No que concerne à educação, a melhoria e ampliação do sistema de ensino nacional vem proporcionando a inclusão de parcela cada vez mais significativa da população. Dessa forma, concomitantemente ao incremento demográfico, o estoque de capital humano vem se expandindo, contribuindo inclusive para a redução relativa do contingente de pessoas não alfabetizadas.

A Tabela 2 abaixo apresenta dados relativos acerca do nível de alfabetização, assim como as participações relativas dos segmentos educacionais, utilizando-se um recorte regional. Observa-se uma acentuada expansão em todos os níveis educacionais entre 1970 e 1991, relacionada principalmente ao aumento no tempo médio de estudo da população acima de 10 anos. Em 1970, esse tempo médio era de apenas 4 anos, ao passo que em 1991 passou a ser de quase 6 anos, sendo ainda bastante reduzido quando comparado ao padrão encontrado nos países desenvolvidos. Em termos

Tabela 2 - REGIÕES DO BRASIL - NÍVEL DE ALFABETIZAÇÃO E PARTICIPAÇÃO RELATIVA DOS NÍVEIS DE EDUCAÇÃO (\%) - 1970 - 1991

\begin{tabular}{lcccccccc}
\hline \multicolumn{1}{c}{ Regiões } & \multicolumn{2}{c}{ Alfabetização } & \multicolumn{2}{c}{ Elementar } & \multicolumn{2}{c}{$1 .^{\circ}$ Grau } & \multicolumn{2}{c}{$2 .^{\circ}$ Grau } \\
& 1970 & 1991 & 1970 & 1991 & 1970 & 1991 & 1970 & 1991 \\
\hline \hline & & & & & & & & \\
Norte & 54,32 & 57,18 & 10,62 & 29,76 & 4,14 & 14,92 & 1,13 & 9,24 \\
Nordeste & 39,21 & 49,17 & 7,62 & 27,75 & 2,73 & 11,54 & 0,92 & 9,35 \\
Sudeste & 71,56 & 78,00 & 26,56 & 41,75 & 13,01 & 20,67 & 6,03 & 14,96 \\
Sul & 70,12 & 83,98 & 40,09 & 59,00 & 12,22 & 23,01 & 7,41 & 14,58 \\
Centro-Oeste & 56,69 & 68,64 & 26,11 & 46,28 & 13,66 & 21,05 & 4,96 & 10,96 \\
\hline \hline Brasil & 60,34 & 76,94 & 27,54 & 41,66 & 12,47 & 18,75 & 5,59 & 11,57 \\
\hline \hline
\end{tabular}

FONTE: IBGE. Censos Demográficos. 
relativos, as regiões "periféricas" - Norte, Nordeste e Centro-Oeste - foram as que mais expandiram sua base educacional, corroborando assim para a hipótese básica na qual se assenta este trabalho.

\section{ANÁLISE DOS RESULTADOS}

Procura-se, neste segmento, expor os resultados econométricos da estimação do modelo adotado. Optou-se pela análise dos resultados a partir de duas perspectivas espaciais: uma a nível inter-microrregional - quando todas as microrregiões brasileiras são consideradas conjuntamente, e outra a nível inter-regional - no qual as microrregiões são agrupadas, seguindo-se o limite geográfico de cada uma das grandes regiões. O intervalo de tempo analisado compreende o período 1970 a 1996.

Os resultados das estimações encontram-se relacionados na Tabela 3. Nesta etapa, foram estimadas regressões, examinando as 534 microrregiões brasileiras de forma conjunta. Na primeira especificação, procurou-se verificar a existência de um processo de convergência absoluta. Calculou-se então uma regressão, utilizando as taxas de crescimento do PIB per capita das microrregiões entre 1970 e 1996 contra o log do PIB do ano inicial. Observase que o coeficiente da variável independente apresentou sinal negativo, sugerindo que as microrregiões mais pobres apresentaram taxas de crescimento mais elevadas do que as micros mais ricas. $O$ índice $\beta$ estimado, que demonstra a velocidade de convergência, foi da ordem de $0,36 \%$ ao ano. Esse coeficiente foi aceito como estatisticamente significativo ao nível de $95 \%$ de confiança. Todavia, o grau de ajustamento da regressão $\left(\mathrm{R}^{2}\right)$, de $0,26 \%$, foi muito baixo, sugerindo a pouca aderência do PIB per capita no ano inicial à taxa de crescimento da renda no período estudado.

Diante desses resultados, procurou-se estimar outras especificações, a fim de encontrar evidências mais robustas para a hipótese da convergência. Foram incluídas variáveis dummies para as microrregiões onde se localizam as capitais dos Estados, no intuito de realçar os efeitos polarizantes das capitais vis-à-vis às demais micros. Nesse contexto, a velocidade de convergência estimada foi da ordem de $0,40 \%$, apenas um pouco acima da especificação anterior, sendo ainda aceita como estatisticamente válida. Esse resultado sugere, no entanto, que o impacto das micros das capitais não desempenharam por si só papel preponderante na qualificação do processo de convergência a nível nacional.

Nas três especificações subseqüentes, foram incluídas variáveis educacionais, considerando-se conjuntamente todas as microrregiões 
VERGOLINO, J. R. et al. Crescimento econômico regional no Brasil...

Tabela 3 - MICRORREGIÕES DO BRASIL - RESULTADOS DAS ESTIMAÇÕES DAS VELOCIDADES ß-CONVERGÊNCIA - 1970 - 1996

\begin{tabular}{|c|c|c|c|c|c|c|c|c|c|}
\hline Discriminação & 1 & 2 & 3 & 4 & 5 & 6 & 7 & 8 & 9 \\
\hline \multirow[t]{2}{*}{ Beta } & $0,36 \%$ & $0,40 \%$ & $0,63 \%$ & $0,37 \%$ & $0,42 \%$ & $1,11 \%$ & $1,30 \%$ & $1,60 \%$ & $1,56 \%$ \\
\hline & $(0,0001)$ & $(0,0000)$ & $(0,0000)$ & $(0,0001)$ & $(0,0001)$ & $(0,0000)$ & $(0,0000)$ & $(0,0000)$ & $(0,0000)$ \\
\hline $\mathrm{T}_{\mathrm{MV}}$ & 193 & 173 & 110 & 187 & 165 & 62 & 53 & 43 & 44 \\
\hline \multirow[t]{2}{*}{ Dummy Capitais } & & $0,005^{*}$ & & & & & & & \\
\hline & & $(0,1454)$ & & & & & & & \\
\hline \multirow[t]{2}{*}{ Dummy NO } & & & & & & 0,1035 & 0,1178 & 0,1435 & 0,1425 \\
\hline & & & & & & $(0,0000)$ & $(0,0000)$ & $(0,0000)$ & $(0,0000)$ \\
\hline \multirow[t]{2}{*}{ Dummy NE } & & & & & & 0,1063 & 0,1191 & 0,1414 & 0,1401 \\
\hline & & & & & & $(0,0000)$ & $(0,0000)$ & $(0,0000)$ & $(0,0000)$ \\
\hline \multirow[t]{2}{*}{ Dummy SD } & & & & & & 0,1278 & 0,1410 & 0,1676 & 0,1637 \\
\hline & & & & & & $(0,0000)$ & $(0,0000)$ & $(0,0000)$ & $(0,0000)$ \\
\hline \multirow[t]{2}{*}{ Dummy S } & & & & & & 0,1297 & 0,1416 & 0,1677 & 0,1677 \\
\hline & & & & & & $(0,0000)$ & $(0,0000)$ & $(0,0000)$ & $(0,0000)$ \\
\hline \multirow[t]{2}{*}{ Dummy CO } & & & & & & 0,1231 & 0,1360 & 0,1629 & 0,1622 \\
\hline & & & & & & $(0,0000)$ & $(0,0000)$ & $(0,0000)$ & $(0,0000)$ \\
\hline \multirow[t]{2}{*}{ Elementar } & & & 0,0257 & & & & 0,0201 & & \\
\hline & & & $(0,0000)$ & & & & $(0,0001)$ & & \\
\hline \multirow[t]{2}{*}{$1 .^{\circ} \mathrm{grau}$} & & & & 0,0569 & & & & 0,2787 & \\
\hline & & & & $(0,0094)$ & & & & $(0,0000)$ & \\
\hline \multirow[t]{2}{*}{ 2. ${ }^{\circ}$ grau } & & & & & $0,0232 *$ & & & & 0,3249 \\
\hline & & & & & $(0,3215)$ & & & & $(0,0000)$ \\
\hline $\mathrm{R}^{2}$ & 0,026 & 0,030 & 0,058 & 0,038 & 0,028 & 0,282 & 0,301 & 0,323 & 0,320 \\
\hline $\mathrm{F}$ & 14,35 & 8,25 & 16,53 & 10,64 & 7,66 & 34,71 & 32,54 & 36,01 & 35,49 \\
\hline
\end{tabular}

NOTA: $\mathrm{T}_{\mathrm{MV}}=$ números de anos necessários para que o gap entre as micros mais ricas e as pobres caia a metade. A fórmula utilizada foi $\mathrm{LN}(2) /$ Beta. * = não é significante a $95 \%$ de confiança. Os valores entre parênteses referem-se ao valor-p.

A regressão estimada é a da forma $(1 / T) \cdot \log \left(\mathrm{y}_{\mathrm{it}} / \mathrm{y}_{\mathrm{i}, \mathrm{t}-\mathrm{T}}\right)=\mathrm{a}-\left[\log \left(\mathrm{y}_{\mathrm{i}, \mathrm{t}-\mathrm{T}}\right)\right] \cdot\left[\left(1-\mathrm{e}^{-\mathrm{BT}}\right) / \mathrm{T}\right]+\mathrm{E}_{\mathrm{i}}$

brasileiras. Os resultados apontam o nível elementar como o que mais contribuiu para a velocidade de convergência $(0,63 \%)$. Todavia, o incremento em termos de convergência foi pouco satisfatório.

A inexpressividade dos resultados encontrados, em favor de um processo convergente a nível microrregional, pode ser explicada pelo elevado grau de heterogeneidade no padrão de crescimento das diversas microrregiões brasileiras. Tal fenômeno convalida a tese de que o processo de desenvolvimento econômico brasileiro apresentou uma distribuição espacialmente assimétrica, privilegiando alguns subespaços regionais. Quando as microrregiões brasileiras são tomadas em seu conjunto, as diferenças interregionais entre as microrregiões são tão elevadas que mesmo a inclusão de 
variáveis dummies para as micros onde se localizam as capitais, assim como a inclusão de variáveis educacionais, não atua fortalecendo o processo de equalização das rendas per capita.

Nesse estágio pode-se concluir, em nível preliminar, que a localização geográfica das micros exerce papel preponderante no padrão de crescimento da renda. Assim sendo, a educação, juntamente com um maior nível do PIB per capita, encontrado em algumas regiões, parecem responder de forma mais consistente à diminuição do quadro geral de disparidades. Dessa forma, são os fatores locacionais, pertinentes a cada uma das regiões, os francos responsáveis pelo padrão de crescimento ao longo do período em questão. $\mathrm{O}$ entendimento de como vem se procedendo o impacto das variáveis de educação na promoção do crescimento passa então a ser dimensionado a partir de uma perspectiva regional.

Nesse contexto, procurou-se aprofundar a discussão acerca da hipótese da convergência das rendas per capita, pondo em foco as diferenças inter-regionais, mediante a inclusão de variáveis dummies para cada uma das regiões brasileiras. A inclusão dessas variáveis produziu uma melhoria significativa nos coeficientes das regressões, assim como no grau de ajustamento das mesmas. O coeficiente $\beta$-convergência estimado, da ordem de $1,11 \%$ ao ano, sugere um processo de convergência das rendas per capita no ponto em que as diferenças regionais são explicitadas pelas dummies. Admite-se, dessa forma, a existência de diferentes steady state entre as regiões brasileiras, indicando um alto grau de heterogeneidade entre elas.

A introdução das variáveis educacionais nessa perspectiva permitiu o afloramento de aspectos interessantes da dinâmica microrregional. As evidências econométricas indicam que os investimentos em educação contribuíram para acelerar a velocidade de convergência. Os coeficientes $\beta$ estimados foram de 1,30\%,1,60\% e 1,56\% para os níveis elementar, primeiro e segundo grau respectivamente. Todo o conjunto de coeficientes estimados mostrou-se estatisticamente relevante ao nível de $95 \%$ de confiança.

Os resultados observados sinalizam que as variáveis educacionais mais importantes na aceleração do processo de convergência no Brasil foram as de primeiro e segundo graus. O crescimento do setor de serviços especializados e também de ramos específicos da indústria, exigindo uma mão-de-obra com maior nível de escolarização, é uma indicação que permite avaliar melhor esse fenômeno.

Uma situação educacional relativamente mais favorável, em tais segmentos, engendrou um ganho na produtividade da mão-de-obra, traduzindose em uma melhor distribuição nas taxas de crescimento microrregionais. Contudo, ainda transparecem diferenças inter-regionais quanto ao impacto 
da educação na equalização das rendas regionais, abrindo espaço para uma discussão, nos seus pormenores, dos ganhos de produtividade ocorridos a nível de cada região.

O corolário dessa observação é a necessidade de se inferir acerca do padrão de crescimento econômico, a partir de um plano intra-regional, ou seja, dentro de cada região. Nesse intuito, optou-se por agrupar as microrregiões seguindo o limite geográfico de cada região. Os resultados dos testes encontram-se sumarizados na Tabela 4 seguinte.

Em termos de convergência absoluta, os resultados das estimações para as regiões Sul e Norte do país apontam para uma distribuição espacial mais simétrica do processo de desenvolvimento econômico intra-regional. As velocidades $\beta$-convergência para essas regiões foram de 1,91\% e 1,65\%, respectivamente, indicando que as microrregiões mais pobres engendraram um processo consistente de crescimento econômico, resultando na diminuição do gap existente para com as micros mais ricas. Nas demais regiões analisadas, as baixas taxas encontradas para o $\beta$-convergência não indicam a existência de um processo convergente mais significativo.

Tabela 4 - GRANDES REGIÕES - RESULTADOS DAS ESTIMAÇÕES DAS VELOCIDADES ß-CONVERGÊNCIA - 1970 - 1996

\begin{tabular}{lccccc}
\hline \hline \multicolumn{1}{c}{ Regiões } & $\begin{array}{c}\text { N. }^{\circ} \text { de } \\
\text { Observa- } \\
\text { ções }\end{array}$ & Convergência & \multicolumn{3}{c}{ Convergência Condicional } \\
& \multirow{2}{*}{53} & 0,0165 & 0,0330 & 0,0460 & 0,0420 \\
\hline \hline Norte & & $(0,0202)$ & $(0,0010)$ & $(0,0000)$ & $(0,0000)$ \\
& & 42 & 21 & 15 & 17 \\
$\mathrm{~T}_{\text {MV NO }}$ & \multirow{2}{*}{$\begin{array}{c}\text { Absoluta } \\
\text { Nordeste }\end{array}$} & 0,0080 & 0,0170 & 0,0150 & 0,0150 \\
& & $(0,0000)$ & $(0,0000)$ & $(0,0000)$ & $(0,0000)$ \\
$\mathrm{T}_{\text {MV NE }}$ & & 87 & 41 & 46 & 46 \\
Sudeste & 159 & 0,0095 & 0,0160 & 0,0110 & 0,0140 \\
& & $(0,0000)$ & $(0,0000)$ & $(0,0000)$ & $(0,0000)$ \\
$\mathrm{T}_{\text {MV SD }}$ & & 73 & 43 & 63 & 50 \\
Sul & 94 & 0,0191 & 0,0320 & 0,0300 & 0,0290 \\
& & $(0,0000)$ & $(0,0000)$ & $(0,0000)$ & $(0,0000)$ \\
$\mathrm{T}_{\text {MV S }}$ & & 36 & 22 & 23 & 24 \\
Centro-Oeste & 43 & $0,0069^{*}$ & $0,0080^{*}$ & $0,0110^{*}$ & $0,0090^{*}$ \\
& & $(0,0813)$ & $(0,0630)$ & $(0,0260)$ & $(0,0730)$ \\
$\mathrm{T}_{\text {MV C.O }}$ & & 100 & 87 & 63 & 77 \\
\hline \hline
\end{tabular}

NOTA: $\mathrm{T}_{\mathrm{MV}}=$ números de anos necessários para que o gap entre as micros mais ricas e as pobres caia a metade. A fórmula utilizada foi $\mathrm{LN}(2) /$ Beta. * = não é significante a $95 \%$ de confiança. 
A seguir são apresentados gráficos para as grandes regiões brasileiras, excetuando-se o Centro-Oeste, para o qual os resultados das regressões não se mostraram válidos. Tais gráficos confrontam o logaritmo do PIB per capita com a taxa de crescimento do PIB para o período 1970-1996, a fim de indicar a direção seguida pelo processo de convergência absoluta. Observa-se, em primeira análise, que todas as regiões representadas exibem tendência para a convergência nas rendas entre as suas microrregiões, à imagem do que foi apontado pelos testes econométricos. Contudo, as regiões Norte e Sul se destacam pelo menor grau de dispersão apresentado, favorecendo uma maior velocidade de convergência. Nessas regiões, as micros mais pobres alvitraram uma elevação relativa de seu produto maior do que as micros mais ricas, contribuindo para a redução do quadro de disparidades intra-regional. Deixa-se claro, todavia, que essa medida - a da convergência absoluta - não deixa evidente as mudanças de caráter qualitativo ocorridas. Em outras palavras, consegue-se demonstrar o processo de crescimento econômico per $s i$, porém não se consegue demonstrar se o mesmo se deu de forma socialmente igualitária entre as microrregiões, ou, ainda mais especificamente, dentro de cada uma das microrregiões.
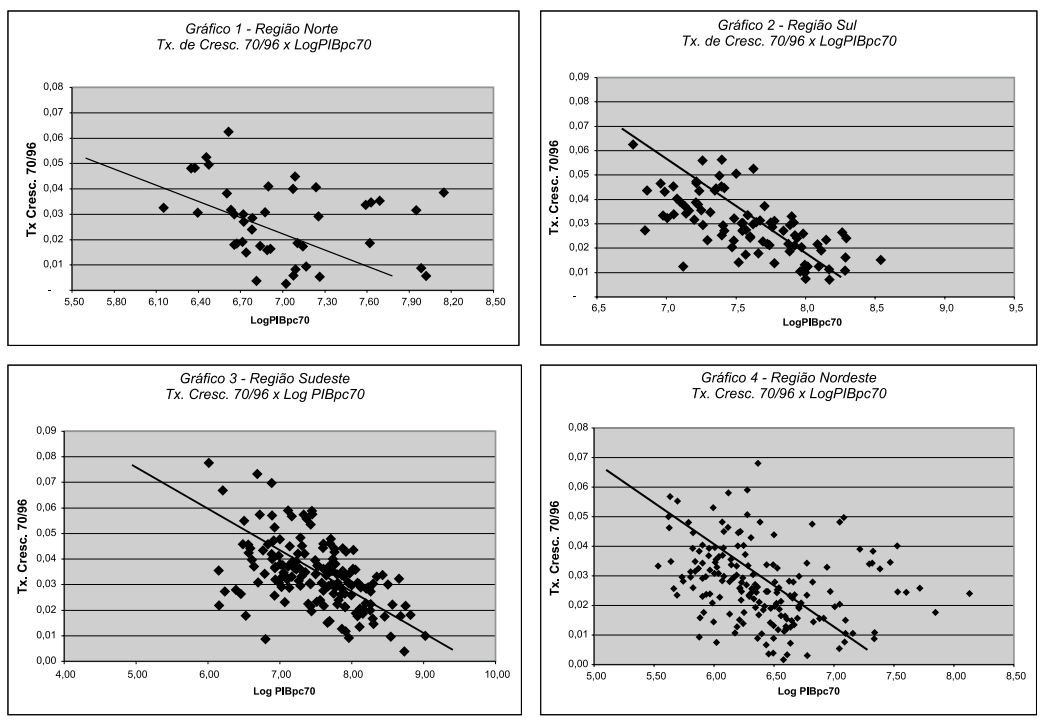
Mesmo assinalando-se, mediante os resultados obtidos, quanto à redução das diferenças entre microrregiões - na perspectiva regional adotada - ainda persistem discrepâncias de magnitude apreciável nos indicadores de renda per capita. De fato, a trajetória de crescimento econômico no período 1970/1996 seguiu por caminhos diferentes no que tange às regiões em si, podendo assumir contornos ainda mais relevantes quando tomadas em seu conjunto.

Ainda que se haja bem-vista a mudança de paradigma experimentada pelo Brasil no período objeto de análise, onde uma nação em princípios de industrialização deu lugar a uma outra, industrializada e mais integrada do ponto de vista regional, ainda são os fatores ligados à localização geográfica, bem como o papel do governo federal como agente redutor de disparidades regionais, alguns dos francos responsáveis no que se pode chamar de "bases para o crescimento".

A explicação para a dispersão existente nas rendas microrregionais não é trivial, em virtude das especificidades de cada região e o papel desempenhado por cada uma delas dentro da economia brasileira. Com relação ao Norte do país, alguns fatores de caráter bastante específico colocam essa região numa posição singular, quando comparada com as demais. Inicialmente, os grandes fluxos migratórios ocorridos na década de 70 - etapa principal do povoamento e da diversificação das atividades produtivas dessa região engendraram um considerável aumento de seu mercado interno, vencendo pouco a pouco as debilidades internas em vigor até então, principalmente nos setores sociais e de infra-estrutura.

A importância da migração sobre a evolução populacional da Região Norte tem sido historicamente relevante. Segundo estudo de Martine e Turchi, em 1980 cerca de 48,3\% da população com domicílio em áreas urbanas era constituída por migrantes. Nessa leva de migrantes, o nível educacional relativamente elevado constituiu um efeito populacional positivamente diferenciado, isto é, permitiu a formação de uma parcela significativa da população de maior nível educacional em relação à população total.

Como tal, houve uma rápida expansão do produto regional, ocorrendo de forma simultânea um grande aporte de recursos públicos, canalizados tanto para a infra-estrutura como para suprir a crescente demanda social por serviços básicos, dentre eles saúde, educação e habitação. Os investimentos públicos, mais especificamente, foram de grande relevância devido a seu caráter espacialmente abrangente, permitindo, assim, uma maior integração econômica daquelas microrregiões mais afastadas dos grandes centros urbanos. 
No tocante ao Sul do país, a expansão do setor agroindustrial nacional teve nessa região o seu mais forte impulso. Boa parte da pauta de exportações agrícolas brasileiras é oriunda do Sul, promovendo uma maior dinamização dos setores produtivos localizados fora do eixo principal das capitais dos Estados. Em adição, sua posição geográfica privilegiada vem transformando-a num corredor de ligação das demais regiões brasileiras com os países situados no Cone Sul. Nesse contexto, a Região Sul vem apresentando a mais alta taxa de convergência dentre as demais regiões, com um $\mathrm{T}_{\text {meia vida }}{ }^{6}$ estimado de 36 anos. Esse resultado está bastante próximo do encontrado por Barro e Sala-I-Martin (1995) em estimações realizadas para os quarenta e oito estados norte-americanos (34 anos); e também para as prefeituras japonesas (36 anos) $)^{7}$.

Nas demais regiões, ainda com relação aos resultados encontrados para a convergência absoluta, as regiões Nordeste e Sudeste apresentaram indicadores de convergência algo próximos (ver tabela), distantes contudo das regiões anteriormente assinaladas. À luz das recentes interpretações associadas a uma dinâmica comportamental como essa, pode-se comentar em nível introdutório, dentro do modelo de crescimento brasileiro, a existência de "clubes" de convergência. Em linhas gerais, esses clubes se formam no momento em que algumas regiões passam a crescer acima da média do país, enquanto que outras "patinam" no caminho, crescendo abaixo dessa média.

No caso brasileiro, até mesmo esses clubes parecem ter uma heterogeneidade particular, ao congregar o Norte e o Sul; o Nordeste e o Sudeste, em dois clubes de características ímpares, quando observados a partir das taxas de crescimento da renda per capita. Sua formação, dessa forma, parece estar muito mais relacionada aos acontecimentos internos pertinentes a cada uma delas (como já ressaltado), conciliatoriamente à ação de agentes externos (principalmente o governo federal), do que propriamente às comparações um tanto simplificadoras extraídas a partir das taxas de crescimento. Mais adiante será feito um breve comentário sobre a formação de tais clubes num outro contexto: o da convergência condicional, mas com resultados semelhantes aos já encontrados quando da convergência absoluta.

$6 \quad \mathrm{OT}_{\text {meia vida }}$ corresponde ao número de anos necessários para que as diferenças em termos da renda per capita das regiões se reduza à metade. A fórmula utilizada foi $\mathrm{T}_{\text {meia }}$ vida $=(\ln 2) / \beta$.

Os demais resultados encontrados para o gap em trabalhos internacionais situam-se como segue: Europa (46 anos); Colômbia (17 anos); Canadá (35 anos); México (28 anos). 
Nas especificações a seguir, procurou-se verificar a importância dos investimentos em educação para o processo de convergência das rendas per capita regionais. As variáveis utilizadas, anteriormente já referidas, congregam os níveis elementar, $1^{\circ}$ e $2^{\circ}$ graus. Em primeira análise, a introdução de tais variáveis teve papel altamente relevante no caso brasileiro, contribuindo não só para o crescimento econômico regional como também para a diminuição do gap existente entre as rendas inter-regionais.

Pode-se constatar, a partir da Tabela 4, que em todas as regiões brasileiras as variáveis educacionais aceleraram a velocidade $\beta$-convergência, consectariamente à nova teoria de crescimento econômico abordada neste trabalho. À luz dessa perspectiva, os resultados encontrados conseguiram captar as nuances relativas dos diferentes níveis de educação, em cada região, no processo de desenvolvimento ao longo do período.

Partindo-se do nível elementar, os resultados encontrados sugerem que as Regiões Norte e Sul foram as que mais se beneficiaram com os investimentos nesse segmento educacional. Com efeito, os indicadores de convergência para as regiões aludidas passaram para 3,3\% e 3,2\%, respectivamente. Dessa forma, houve uma significativa redução do $\mathrm{T}_{\text {meia vida }}, \mathrm{o}$ qual alcançou aproximadamente 21 anos para ambas as regiões. Para as demais regiões, esse indicador revelou-se importante, porém menos substancial na aceleração da velocidade de convergência.

Para a perspectiva do nível de educação relativo ao $1^{\circ}$ grau, os resultados guardam certa semelhança com os anteriormente explicitados. $\mathrm{O}$ Norte e o Sul do país continuaram apresentando uma situação de destaque vis-à-vis às demais regiões. Nesse contexto, pode-se verificar a significativa elevação da velocidade de convergência na Região Norte, que alcançou 4,6\%, correspondendo a um aumento de cerca de $40 \%$ em relação ao segmento educacional anterior. Por fim, para o nível de $2^{\circ}$ grau, os coeficientes estimados também apontam para o papel promissor dos investimentos em educação na promoção da equalização das rendas intramicrorregionais, conquanto se situem abaixo do $1^{\circ}$ grau.

De acordo com os resultados econométricos encontrados, pode-se atribuir uma dinâmica comportamental para as regiões brasileiras a partir dos efeitos das variáveis de educação em cada uma delas, ou seja, em termos da convergência condicional. Em linhas gerais, verifica-se novamente a existência de dois clubes de convergência com características bem distintas. No primeiro deles, englobando as regiões Norte e Sul, a ilação dos investimentos em capital humano promoveu de forma mais contundente o processo de convergência das rendas. No segundo, contemplando o restante das regiões, conquanto o fenômeno de convergência fez-se presente, ao serem incluídas 
as variáveis representativas do capital humano, este se mostrou menos dinâmico no período.

Mesmo contendo aspectos considerados válidos, a formação de clubes de convergência a partir da convergência condicional é considerada uma hipótese mais fraca quando comparada à absoluta. Em trabalho que busca verificar a formação de tais clubes na Grã-Bretanha, Chatterji e Dewhurst (1995) assinalam que as diferenças encontradas pelas economias no período inicial (seu steady state) podem interferir nos resultados condicionais. Contudo, a hipótese é plausível, uma vez que a inclusão de novas variáveis no modelo, principalmente relativas ao capital humano, buscando explicar o padrão de crescimento em nível regional, pode conduzir a resultados mais factuais.

No tocante à Região Norte, conforme já comentado, houve ao longo das décadas de 70 e 80 um processo de diversificação da base econômica regional, exigindo uma força de trabalho de melhor qualidade e com maior nível de especialização. O sistema econômico respondeu aos estímulos do setor produtivo ampliando consideravelmente a oferta de mão-de-obra - via migração - privilegiando a de melhor nível educacional.

No que concerne à Região Sul, esta apresentou uma relativa estabilidade nos coeficientes de convergência para os três níveis educacionais estudados. Contudo, a melhor posição inicial dessa região, no tocante ao PIB per capita do período inicial, reforça os resultados mais robustos encontrados para as regressões. Dessa forma, embora o Norte tenha convergido mais rapidamente, foi no Sul que se deu uma maior diminuição na dispersão das rendas intra-regionais (vide Gráficos 1 e 2).

Uma vez que o nível de especialização da mão-de-obra sulina apresenta-se como um dos mais elevados do país, os investimentos em educação engendraram um aumento na produtividade dos fatores de produção, conduzindo a um processo de crescimento econômico espacialmente mais simétrico. A existência de um processo de convergência absoluta, sem se levar em conta os níveis educacionais, indicou por si só que a região em questão experimentou forte incremento em seu nível de produto per capita, fomentando uma maior desconcentração da atividade produtiva. Contudo, a existência desse processo foi dinamizada mediante os investimentos em educação, de tal maneira que esta propiciou externalidades positivas para a economia, acelerando a velocidade de convergência.

Os resultados encontrados para a Região Nordeste apontam para uma tênue equalização das rendas per capita entre as suas microrregiões. A velocidade $\beta$-absoluta estimada, de apenas $0,80 \%$, indica que serão necessários 86 anos para que as diferenças microrregionais se reduzam à metade. À luz 
desse resultado, a incorporação de variáveis educacionais provocou uma sensível aceleração do processo de convergência.

$\mathrm{O}$ fato notável está relacionado à diferença na magnitude dos parâmetros de convergência condicional, aproximadamente o dobro daquela estimada para o $\beta$-absoluto. Isso indica, em uma primeira aproximação, que a grande força motriz do processo de convergência na Região Nordeste foram os investimentos no setor educacional. Por outro lado, deve-se destacar a estabilidade dos coeficientes $\beta$-condicional, que se situaram no intervalo de $1,5 \%$ a $1,7 \%{ }^{8}$.

Nessa região, onde se fazem presentes grandes diferenças intraregionais, existem alguns subespaços bastante dinâmicos, em contraste com os demais, essencialmente agrícolas. Naqueles subespaços mais dinâmicos, os investimentos na formação de pessoal qualificado, principalmente ao nível do $2^{\circ}$ grau, responderam pelo forte incremento em seu produto no período 1970-1996. No tocante à porção agrícola da região, o maior incremento na produtividade da mão-de-obra, medido pelas elasticidades dos indicadores, apontaram o ensino elementar como o de maior peso.

Por fim, na Região Sudeste, os resultados das regressões também apontam a educação como fator-chave no processo de convergência. Com um $\beta$-absoluto de $0,95 \%$, a inclusão das variáveis de educação conduzem a indicadores variando entre $1,1 \%$ a $1,6 \%$. O tempo estimado para a redução das disparidades microrregionais cai de 72 anos para a média de 52 anos. No caso da Região Sudeste, muito embora a educação consiga explicar satisfatoriamente a convergência nas rendas per capita microrregionais, é mister considerar que sendo essa região a mais rica do país, outros fatores, dentre eles a maior acumulação de capital ocorrido no período, podem ter conduzido a uma maior aceleração na velocidade de convergência, superior àquela captada nos moldes do modelo estudado.

A Região Centro-Oeste, por seu turno, não apresentou resultados econométricos significativos nos coeficientes estimados. Dessa forma, não se pôde explicitar de forma mais acurada a tendência de um processo de convergência nas rendas microrregionais, nem o papel da educação nesse contexto.

8 Resultados semelhantes foram encontrados em Barros (1998). 


\section{CONCLUSÕES}

No presente trabalho, adotou-se duas perspectivas espaciais no intuito de examinar a hipótese da convergência das rendas per capita no Brasil. Na primeira dimensão, utilizou-se os dados das microrregiões brasileiras tomadas em seu conjunto. Na segunda, optou-se pela análise das microrregiões a partir de uma base de dados regional, isto é, separou-se as micros de acordo com as regiões nas quais estão localizadas.

Os resultados apresentados ao longo das páginas precedentes para as microrregiões em seu conjunto mostraram-se coerentes com o previsto pela teoria. Ao nível do $\beta$-absoluto, a velocidade estimada foi de $0,36 \%$, passando para $0,40 \%$ quando consideradas variáveis dummy para as microrregiões das capitais. Introduzindo as variáveis educacionais, os coeficientes estimados foram de $0,63 \%, 0,37 \%$ e $0,42 \%$ para os níveis elementar, de $1^{\circ}$ e $2^{\circ}$ graus, respectivamente. Em linhas gerais, a análise a partir dessa perspectiva mostrou, do ponto de vista econométrico, resultados bastante pobres.

Apenso a esse fato, introduziu-se na regressão variáveis dummy regionais, ou seja, buscou-se captar os efeitos das diferenças inter-regionais no processo de equalização das rendas regionais. Nesse contexto, a velocidade de convergência estimada passa a ser de $1,11 \%$, com resultados econométricos bem mais robustos do que os anteriormente encontrados. Com a introdução das variáveis educacionais, os coeficientes $\beta$-condicionais estimados passaram a ser de $1,30 \%, 1,60 \%$ e $1,56 \%$, respectivamente, para os três níveis educacionais utilizados.

Mediante a importância assumida pelas diferenças inter-regionais no processo de convergência, optou-se pela análise em uma perspectiva regional. Nesse aspecto, os coeficientes $\beta$-absolutos estimados se mostraram mais elevados do que na dimensão anterior, notadamente os verificados para a Região Norte $(1,65 \%)$ e para a Região Sul $(1,91 \%)$. No que concerne a esse indicador, bem como no de convergência condicional, verificou-se a existência de dois clubes de convergência, o primeiro deles compreendendo as regiões Norte e Sul, e o outro, as demais regiões.

No primeiro deles, pôde-se observar uma maior dinâmica nos coeficientes $\beta$-condicional para os três níveis educacionais, os quais se mostraram os mais elevados dentre todos aqueles estimados, sugerindo que os investimentos em educação alvitraram um maior ganho de produtividade para essas economias. No segundo, os resultados sugerem um processo de convergência nas rendas per capita regionais, entretanto, de menor magnitude 
do que no clube anterior. Contudo, a educação também incrementou a produtividade de maneira geral nessas regiões.

À guisa de conclusão, as evidências apresentadas ao longo deste trabalho apontam para o fato de que as diferenças inter-regionais possuem importância destacada no entendimento da dinâmica do crescimento econômico brasileiro. Por fim, a importância dos investimentos em educação para a aceleração do processo de convergência das rendas per capita foi determinante em todas as especificidades estudadas, corroborando a tese de que países mais pobres têm condições de reduzir seus quadros de desigualdades a partir do desenvolvimento de um programa de incentivo à formação de capital humano.

\title{
RESUMO
}

Este trabalho tem como principal objetivo analisar o papel da educação no processo de crescimento econômico das microrregiões brasileiras no período de 1970-1996. A hipótese central do trabalho é a de que tal processo apresentou tendência convergente, sinalizando uma redução nas disparidades inter-regionais. Utilizando-se a metodologia proposta por Barro e Sala-I-Martin, foram estimadas regressões a partir do uso do método dos mínimos quadrados ordinários, a fim de captar a existência do fenômeno da convergência e identificando a velocidade ( $\beta$ ) pela qual o mesmo se processa. Por fim, procurou-se verificar a importância da educação na equalização das rendas per capita microrregionais. Os resultados encontrados apontam para a existência de um processo convergente nas rendas microrregionais, quando consideradas as variáveis educacionais. Palavras-chave: educação, crescimento, Brasil.

\begin{abstract}
The main purpose of this paper is to analyze the role of education in the process of economic growth for the Brazilian microrregions during the period 1970-1996. The hypothesis is that economic growth associated with educational improvements has led to a reduction in the inter-regional disparities in that period. Following the methodology proposed by Barro e Sala-I-Martin, regressions were estimated using the method of ordinary least squares, in order to identify the existence of the convergent process and the convergence
\end{abstract}


velocity $(\beta)$ of the former. The importance of education in the equalization of per capita microrregional income were also discussed. The results support the hypothesis under which human capital plays an important role in the economic growth of a region or country. Key-words: education, growth, Brazil.

\section{REFERÊNCIAS}

AZZONI, C. R. Economic growth and regional income inequalities in Brazil 193992. USP discussion paper, 1996.

BARRO, R. J. Economic Growth in a cross section of Countries, Quarterly. Journal of Economics, v. 106, p. 407-443, 1991.

BARRO, R. J.; SALA-I-MARTIN, X. Economic growth. London: McGraw-Hill, 1995.

BARROS, M. A. B.; VERGOLINO, J. R. Educação, crescimento e convergência do PIB per capita do Nordeste do Brasil: uma análise microrregional - 1970-1991. Revista Econômica do Nordeste. v. 29, n. especial, p. 805-826, 1998.

BARROS, M. A. Educação, crescimento e convergência do PIB per capita do Nordeste do Brasil: uma análise microrregional - 1970-1991. Recife, 1998. Dissertação (Mestrado) - PIMES, Universidade Federal de Pernambuco.

BAUMOL. W. J. Productivity growth, converge, and welfare: what the long-run data show. American Economic Review, v. 76, n. 5, p. 1072-1085, Dec. 1986.

CARDENAS, M.; PONTÓN, A. Growth and converge in Colombia: 1955-1990. Journal of Development, v. 47, p. 5-37, 1995.

CARLINO, G.; MILLS, L. Are U.S. Regional Incomes Converging? Journal of Monetary Economics, n. 32, p. 335-346, 1993.

CHATTERJI, M.; DEWHURST, J. Convergence clubs and relative economic performance in Great Britain. Regional Studies, 30, p. 31-40, 1995.

$\mathrm{CHO}, \mathrm{D}$. Industrialization, Convergence and Partners of growth. Southern Economic Journal, v. 61, n. 2, p. 398-414, Oct. 1994.

DE LONG, J. B. Productivity growth, convergence, and welfare: comment. American Economic Review, v .78, n. 5, p. 1.138 -54, Dec. 1988.

GALOR, Oded. Convergence? Inference from theoretical models. The Economic Journal, v. 106, n. 437, p. 1056-1069, 1996.

HOFER, H.; WÖRGÖTTER, A. Regional Per Capita Income Convergence in Austria. Regional Studies, v. 31, n. 1, p. 1-12, 1995. 
IBGE - Instituto Brasileiro de Geografia e Estatística. Censos Demográficos 1970 e 1991 . 1980. Censos Econômicos - Indústria, Comércio, Serviços e Agropecuária 1970 e Anuário Estatístico do Brasil 1970 e 1996.

JUAN-RAMÓN, H.; RIVERA-BATIZ, L. Regional Growth in Mexico: 1970-1993. IMF Working Paper, 1996.

LUCAS, R. On the mechanics of economic development. Journal of Monetary Economics, n. 22, p. 3-42, July 1988.

MARTINE, George; TURCHI, Lenita. Urbanização da Amazônia: realidade e significado. In: ENCONTRO NACIONAL DE ESTUDOS POPULACIONAIS, 2 ., 1980. Anais...

ROMER, P. Increasing Returns and Long-run Growth. Journal of Political Economy. n. 94. p. 1.002-1.037, 1986.

SALA-I-MARTIN, T. The Classical Approach to Convergence Analysis. The Economic Journal. v. 106, n. 437. p. 1019-1035, 1996.

SCHULTZ, T. W. O capital humano, investimentos em educação e pesquisa. Rio de Janeiro: Zahar, 1973.

SMITH, D. M. Neoclassical Growth Models and Regional Growth in the US. Journal of Regional Science, v. 18, n. 9. p. 165-181, 1975.

SOLOW, R. M. A Contribution to the Theory of Economic Growth. Quarterly Journal of Economics, v. 70, n. 1, p. 65-94, 1956. 